\title{
Long-Term Renal Safety Between Patients With Chronic Hepatitis B Receiving Tenofovir vs. Entecavir Therapy: A Multicenter Study
}

\section{Young Eun Chon}

CHA Bundang Medical Center

\section{Soo Young Park}

Kyungpook National University

\section{Seung Up Kim}

Yonsei University College of Medicine

\section{Han Pyo Hong}

Yonsei University - Wonju Campus

\section{Jae Seung Lee}

Yonsei University

\section{Hye Won Lee}

Yonsei University College of Medicine

Mi Na Kim

CHA Bundang Medical Center

Jun Yong Park

Yonsei University Wonju College of Medicine

Do Young Kim

Yonsei University College of Medicine

\section{Sang Hoon Ahn}

Yonsei University

Beom Kyung Kim ( $\square$ beomkkim@yuhs.ac)

Yonsei University College of Medicine https://orcid.org/0000-0002-5363-2496

\section{Research Article}

Keywords: antiviral therapy, chronic hepatitis B, eGFR, entecavir, nucleotide analogue, hepatitis B virus, renal insufficiency, renal dysfunction, renal safety, tenofovir

Posted Date: November 1st, 2021

DOI: https://doi.org/10.21203/rs.3.rs-992707/v1 
License: (c) (i) This work is licensed under a Creative Commons Attribution 4.0 International License. Read Full License

Version of Record: A version of this preprint was published at Journal of Viral Hepatitis on February 13th, 2022. See the published version at https://doi.org/10.1111/jvh.13656. 


\section{Abstract \\ Background}

Renal safety is a critical issue in chronic hepatitis $\mathrm{B}(\mathrm{CHB})$ patients receiving long-term entecavir (ETV) or tenofovir disofuroxil fumarate (TDF) therapy. We investigated their effects on estimated glomerular filtration rate (eGFR).

\section{Methods}

Treatment-naïve CHB patients receiving ETV or TDF for $\geq 1$ year were recruited. The eGFR was assessed using the Chronic Kidney Disease Epidemiology Collaboration equation. We calculated average annual percent change (AAPC) in eGFR using Joinpoint regression.

\section{Results}

At beginning of observation, ETV group had unfavorable conditions than TDF group: lower eGFR and higher FIB-4 and APRI than TDF group (all $P<0.001$ ). After 6 years antiviral therapy, the mean eGFR in ETV group $(n=1,793)$ was maintained ( 96.0 at first year to $95.6 \mathrm{~mL} / \mathrm{min} / 1.73 \mathrm{~m}^{2}$ at sixth year; AAPC $-0.09 \%$; $P=0.322)$, whereas that in TDF group $(n=1,240)$ significantly decreased annually $(101.9$ at first year to $96.9 \mathrm{~mL} / \mathrm{min} / 1.73 \mathrm{~m}^{2}$ at sixth year; AAPC $\left.-0.88 \% ; P<0.001\right)$. Notably, in TDF group, even patients without diabetes (AAPC $-0.80 \% ; P=0.001$ ) or hypertension (AAPC $-0.87 \% ; P=0.001$ ) experienced significant decrease in eGFR. Expectably, accompanying diabetes (AAPC $-1.59 \% ; p=0.011$ ) or hypertension (AAPC $-1.00 \% ; \mathrm{p}=0.002$ ) tended to accelerate eGFR decrease. TDF treatment (odds ratio $1.66, P<0.001$ ), along with eGFR $<60 \mathrm{~mL} / \mathrm{min} / 1.73 \mathrm{~m}^{2}$, serum albumin $<3.5 \mathrm{mg} / \mathrm{dL}$, and hypertension, were independently associated with ongoing renal dysfunction, defined as a negative slope of the mean eGFR change.

\section{Conclusions}

Compared to ETV, long-term TDF treatment induced slow, but progressive renal dysfunction. Although the annual eGFR change by TDF was small, careful monitoring is necessary, especially in patients requiring life-long therapy.

\section{Introduction}

Chronic hepatitis B virus (HBV) infection is a major public health problem affecting approximately 257 million people worldwide [1]. Patients with high serum HBV-DNA levels are more likely to develop liver cirrhosis, hepatic decompensation, and hepatocellular carcinoma (HCC) $[2,3]$. Thus, suppression of HBDNA through antiviral therapy (AVT) using oral nucleos[t]ide analogues (NUCs) has become the major 
basis for treatment of HBV infection [4-8]. Currently, two prominent oral NUCs with high antiviral efficacy and minimal resistance, entecavir (ETV) and tenofovir disoproxil fumarate (TDF), are recommended in the initial treatment of $\mathrm{CHB}$ according to the clinical guidelines [4-6]. Since oral NUCs can effectively suppress HBV replication, but not eradicate intra-hepatic virus itself, their use should be life-long in most patients. Therefore, along with the issue of antiviral efficacy, the long-term safety of oral NUCs has become a concern.

Of their potential adverse effects, renal safety is the most important given that the medications are known to be excreted by renal filtration. Furthermore, chronic kidney disease is more often associated with patients with $\mathrm{CHB}$ than with non-CHB controls [9]. For instance, $\mathrm{CHB}$ patients with cirrhosis are more likely to develop renal insufficiency, including acute kidney injury or hepatorenal syndrome, due to reduced renal blood flow and hemodynamic disturbances [10]. Furthermore, renal tubular dysfunction and Fanconi syndrome have been associated with TDF therapy for a decade [11-13]. Subsequently, several studies have reported the comparative analyses of renal function between patients receiving ETV and TDF; however, these studies had small sample sizes $[14,15]$ and short follow-up periods $[16,17]$. Moreover, in most previous studies, renal dysfunction was defined at a cross-sectional level, that is, only a decrease in the estimated glomerular filtration rate (eGFR) at one or two time points $[13,18]$.

In this multicenter study, we aimed to investigate the long-term effects of ETV and TDF on renal function in a large-scale study population by assessing the serial changes in renal function in the long-term.

\section{Methods}

\section{Patients}

Treatment-naïve CHB patients who received AVT with either daily $0.5 \mathrm{mg}$ ETV (ETV group) or $300 \mathrm{mg}$ TDF (TDF group) as the first-line regimen between 2007 and 2018 in the Division of Gastroenterology and Hepatology at three academic teaching hospitals in the Republic of Korea (Yonsei University Severance Hospital, Kyungpook National University Hospital, and Cha Bundang Medical Center), were screened for eligibility. The exclusion criteria were as follows: (1) age <19 years, (2) history of HCC at enrollment, (3) decompensated cirrhosis at enrollment, (4) AVT for less than 12 months, (5) co-infection with human immunodeficiency virus (HIV) or other hepatitis viruses, (6) history of organ transplantation, and (7) HCC occurrence within 6 months of enrollment (Supplementary Figure 1).

The reimbursement criteria for ETV and TDF in the Republic of Korea are identical (Supplementary Table 1). If histologic information was not available, cirrhosis was clinically defined according to the following criteria: (1) platelet count $<150,000 / \mu \mathrm{L}$ and ultrasonographic findings suggestive of compensated cirrhosis, including a blunted, nodular liver surface accompanied by splenomegaly $(>12 \mathrm{~cm})$; or (2) clinical signs of portal hypertension, such as gastroesophageal varices.

The study protocol complied with the ethical guidelines of the 1975 Declaration of Helsinki and was approved by the institutional review board of each institute. Informed consent was waived because of the 
retrospective nature of the study.

\section{Clinical evaluation and follow-up}

During follow-up, patients underwent routine laboratory tests, including serum creatinine and HBV-DNA levels as well as other viral markers that were monitored at 3-6-month intervals. Patients were screened for HCC and cirrhotic complications every 6 months using ultrasonography and serum alpha-fetoprotein levels [19-22].

Each patient's renal function was monitored every 3-6 months. The eGFR was calculated using the Chronic Kidney Disease Epidemiology Collaboration equation (CKD-EPI): $e G F R=141 \times \min \left(S_{C r} / K, 1\right)^{a} \times$ $\max \left(S_{C r} / K, 1\right)^{-1.209} \times 0.993^{A g e} \times 1.018$ (if female) $\times 1.159$ (if black) [23]. Renal insufficiency was defined as an eGFR $<60 \mathrm{~mL} / \mathrm{min}$, as calculated by the CKD-EPI equation.

\section{Abbreviations / Units}

eGFR (estimated glomerular filtration rate) $=\mathrm{mL} / \mathrm{min} / 1.73 \mathrm{~m}^{2}$

$\mathrm{S}_{\mathrm{Cr}}($ standardized serum creatinine $)=\mathrm{mg} / \mathrm{dL}$

$\mathrm{K}=0.7$ (females) or 0.9 (males)

$a=-0.329$ (females) or -0.411 (males)

$\min =$ indicates the minimum of $\mathrm{S}_{\mathrm{Cr}} / \mathrm{K}$ or 1

$\max =$ indicates the maximum of $\mathrm{S}_{\mathrm{Cr}} / \mathrm{K}$ or 1

\section{Statistical analysis}

Data are presented as mean \pm standard deviation, or number (\%) as appropriate. Differences among continuous and categorical variables were compared using Student's $t$-test and chi-squared test, respectively. To evaluate the change in eGFR during the 6 years of observation, we used the Joinpoint regression method to calculate the average annual percent change (AAPC) in eGFR, odds ratio (ORs), and 95\% confidence interval $(\mathrm{CI})$. Logistic regression analysis was performed to investigate the predictors of ongoing renal dysfunction; ORs and $95 \% \mathrm{Cls}$ were also calculated. Subsequently, a multivariate regression analysis was performed to assess the independent association between the univariate predictors and ongoing renal dysfunction.

All statistical analyses were conducted using SAS software (v9.4; SAS Institute, Cary, NC, USA) and R (v3.6.0, http://cran.r-project.org/). Two-sided p-values $<0.05$ were considered to indicate statistical significance. 


\section{Results}

\section{Baseline characteristics}

A total of 3,033 patients with CHB who were treated with daily ETV $(0.5 \mathrm{mg})$ or TDF $(300 \mathrm{mg})$ as the firstline antiviral regimen for at least 1 year were analyzed. Table 1 describes the clinical characteristics of these patients at the first year of AVT. The mean age of the cohort was 48.8 years, and men were predominant $(63.8 \%)$. Liver cirrhosis was noted in $852(28.1 \%)$ patients, with mean APRI and FIB-4 scores of 0.63 , and 2.38 , respectively. The mean creatinine and eGFR calculated using the CKD-EPI equation were $0.9 \mathrm{mg} / \mathrm{dL}$, and $92.8 \mathrm{~mL} / \mathrm{min} / 1.73 \mathrm{~m}^{2}$, respectively. 
Table 1

Clinical characteristics of patients at 1 year of AVT $(n=3,033)$

\begin{tabular}{|c|c|c|c|c|}
\hline Variables & All & $\begin{array}{l}\text { ETV } \\
(n=1,793)\end{array}$ & $\begin{array}{l}\text { TDF } \\
(n=1,240)\end{array}$ & $\begin{array}{l}P \\
\text { value }\end{array}$ \\
\hline Age (years) & $48.8 \pm 11.6$ & $48.7 \pm 11.4$ & $48.9 \pm 11.8$ & 0.735 \\
\hline Male gender & $\begin{array}{l}1,936 \\
(63.8)\end{array}$ & $1,134(63.2)$ & $802(64.7)$ & 0.442 \\
\hline Body mass index $\left(\mathrm{kg} / \mathrm{m}^{2}\right)$ & $23.7 \pm 3.7$ & $23.8 \pm 4.3$ & $23.6 \pm 2.8$ & 0.185 \\
\hline Diabetes mellitus & $247(8.1)$ & $159(8.9)$ & $88(7.1)$ & 0.091 \\
\hline Hypertension & $271(8.9)$ & $174(9.7)$ & $97(7.8)$ & 0.080 \\
\hline Liver cirrhosis & $852(28.1)$ & $509(28.4)$ & $343(27.7)$ & 0.681 \\
\hline HBeAg positivity & $\begin{array}{l}1,501 \\
(49.5)\end{array}$ & $891(59.4)$ & $610(40.6)$ & 0.796 \\
\hline HBV-DNA $\left(\log _{10} \mathrm{lU} / \mathrm{ml}\right)$ & $5.8 \pm 6.0$ & $5.4 \pm 5.9$ & $5.9 \pm 5.8$ & 0.890 \\
\hline AST (IU/L) & $30 \pm 30$ & $31 \pm 36$ & $29 \pm 17$ & 0.038 \\
\hline ALT (IU/L) & $30 \pm 24$ & $29 \pm 27$ & $29 \pm 17$ & 0.394 \\
\hline Albumin (g/dL) & $4.3 \pm 0.5$ & $4.3 \pm 0.5$ & $4.3 \pm 0.5$ & 0.647 \\
\hline Total bilirubin $(\mathrm{g} / \mathrm{dl})$ & $0.9 \pm 0.8$ & $0.9 \pm 0.9$ & $0.8 \pm 0.5$ & 0.003 \\
\hline Gamma-glutamyl transpeptidase (IU/L) & $77 \pm 99$ & $79 \pm 100$ & $66 \pm 96$ & 0.027 \\
\hline Platelet count $\left(\times 10^{9} / \mathrm{L}\right)$ & $165 \pm 79$ & $160 \pm 86$ & $171 \pm 69$ & $<0.001$ \\
\hline Prothrombin time (INR) & $165 \pm 79$ & $1.0 \pm 0.2$ & $0.9 \pm 0.2$ & 0.320 \\
\hline Serum $\mathrm{Na}(\mathrm{mmol} / \mathrm{L})$ & $141 \pm 3$ & $140 \pm 3$ & $141 \pm 3$ & 0.322 \\
\hline Creatinine $(\mathrm{mg} / \mathrm{dL})$ & $0.9 \pm 0.3$ & $0.9 \pm 0.3$ & $0.8 \pm 0.2$ & $<0.001$ \\
\hline $\begin{array}{l}\text { eGFR by CKD-EPI equation }(\mathrm{ml} / \mathrm{min} / 1.73 \\
\left.\mathrm{m}^{2}\right)\end{array}$ & $98.4 \pm 20.9$ & $96.0 \pm 20.3$ & $101.9 \pm 21.3$ & $<0.001$ \\
\hline FIB-4 index & $2.38 \pm 2.28$ & $2.57 \pm 2.74$ & $2.10 \pm 1.80$ & $<0.001$ \\
\hline APRI score & $0.63 \pm 1.26$ & $0.70 \pm 1.38$ & $0.54 \pm 0.47$ & $<0.001$ \\
\hline \multicolumn{5}{|c|}{ Variables are expressed as mean \pm standard deviation or no. (\%). } \\
\hline \multicolumn{5}{|c|}{$\begin{array}{l}\text { Abbreviations: AVT, antiviral therapy; ETV, entecavir; TDF, tenofovir disoproxil fumarate; HBeAg; } \\
\text { hepatitis B e antigen; } \mathrm{HBV} \text {, hepatitis B virus; AST, aspartate aminotransferase; ALT, alanine } \\
\text { aminotransferase; INR, international normalized ratio; CKD-EPI, Chronic Kidney Disease Epidemiology } \\
\text { Collaboration equation }\end{array}$} \\
\hline
\end{tabular}


At the beginning of the observation period, patients in the ETV group $(n=1,793)$ had significantly unfavorable conditions (higher aspartate aminotransferase level, serum creatinine level, FIB-4 score, and APRI score) than patients in the TDF group $(n=1,240)$ (all $P<0.05)$ (Table 1). In particular, patients in the ETV group had lower eGFRs (mean, $96.0 \mathrm{vs} .101 .9 \mathrm{~mL} / \mathrm{min} / 1.73 \mathrm{~m}^{2}, P<0.001$ ) than those in the TDF group.

\section{Changes in renal function during AVT among the entire cohort}

For the entire cohort $(n=3,033)$, eGFR was measured annually for 6 years after the commencement of AVT (Figure 1). The mean eGFR reduced progressively with statistical significance during 444,673 personyears of follow-up; 98.9, 98.3, 98.0, 97.9, 97.2, and $96.2 \mathrm{~mL} / \mathrm{min} / 1.73 \mathrm{~m}^{2}$ at 1, 2, 3, 4, 5, and 6 years, respectively. The AAPC in eGFR was $-0.49 \%(95 \% \mathrm{Cl} ;-0.61$ to $-0.37, P<0.001)$, showing a trend of significant decrease in the mean eGFR during the 6 year-observation period.

\section{Changes in renal function according to antiviral regimen}

We computed the eGFR at each time point according to treatment with either ETV or TDF (Figure 2 and Table 2). During the 6-year observation period after the commencement of AVT, the mean eGFR was maintained in the ETV group at $96.0 \mathrm{~mL} / \mathrm{min} / 1.73 \mathrm{~m}^{2}$ in the first year and $95.6 \mathrm{~mL} / \mathrm{min} / 1.73 \mathrm{~m}^{2}$ in the sixth year $(P>0.05)$. In contrast, the mean eGFR significantly reduced in the TDF group from 101.9 $\mathrm{mL} / \mathrm{min} / 1.73 \mathrm{~m}^{2}$ after the first of AVT to $96.9 \mathrm{~mL} / \mathrm{min} / 1.73 \mathrm{~m}^{2}$ after 6 years $(P<0.001)$. In the ETV group, the mean eGFR was similarly maintained with an AAPC in eGFR of $-0.09 \%(95 \% \mathrm{Cl},-0.25$ to -0.08 ; $P=0.322$ ). In contrast, among the TDF group, the mean eGFR decreased significantly every year with an AAPC of $-0.88 \%(95 \% \mathrm{Cl},-1.05$ to $-0.71 ; P<0.001)$ 
Table 2

Changes in eGFR in chronic hepatitis B patients treated with ETV or TDF $(n=3,033)$

\begin{tabular}{|c|c|c|c|}
\hline Antiviral regimen & Time after starting AVT & eGFR $\left(\mathrm{ml} / \mathrm{min} / 1.73 \mathrm{~m}^{2}\right)$ & $95 \% \mathrm{Cl}$ \\
\hline ETV & 1 year & $96.0 \pm 20.3$ & $(94.8,97.2)$ \\
\hline \multirow[t]{5}{*}{$(n=1,793)$} & 2 years & $96.3 \pm 19.9$ & $(95.1-97.5)$ \\
\hline & 3 years & $96.7 \pm 20.9$ & $(95.5-97.9)$ \\
\hline & 4 years & $96.5 \pm 19.9$ & $(95.3-97.7)$ \\
\hline & 5 years & $96.1 \pm 19.9$ & $(94.9-97.3)$ \\
\hline & 6 years & $95.6 \pm 19.7$ & $(94.3-96.8)$ \\
\hline \multirow{6}{*}{$\begin{array}{l}\text { TDF } \\
(n=1,240)\end{array}$} & 1 year & $101.9 \pm 21.3$ & $(99.3-104.4)$ \\
\hline & 2 years & $100.3 \pm 21.7$ & $(97.6-102.9)$ \\
\hline & 3 years & $99.4 \pm 22.0$ & $(96.7-102.1)$ \\
\hline & 4 years & $99.4 \pm 21.5$ & $(96.8-102.0)$ \\
\hline & 5 years & $98.3 \pm 21.0$ & $(95.6-100.9)$ \\
\hline & 6 years & $96.9 \pm 19.1$ & $(94.2-99.6)$ \\
\hline \multicolumn{4}{|c|}{ Variables are expressed as mean \pm standard deviation. } \\
\hline
\end{tabular}

\section{Changes in renal function according to comorbidities}

In the ETV group, there was no decrease in the eGFR of patients without diabetes mellitus (AAPC of eGFR, $-0.01 \% ; 95 \% \mathrm{Cl},-0.23$ to $0.22 ; P=0.959$ ) or hypertension (AAPC of eGFR, $0.01 \% ; 95 \% \mathrm{Cl},-0.19,0.21$; $P=0.901)$. However, when diabetes mellitus or hypertension was present, a significant decrease in eGFR was observed; AAPC in eGFR was $-0.84 \%(95 \% \mathrm{Cl},-0.98$ to $-0.70 ; P<0.001)$ in patients with diabetes, and $-1.01 \%(95 \% \mathrm{Cl},-1.38$ to $-0.63 ; P=0.01)$ in those with hypertension.

In contrast, among the TDF group, there was a significant decrease in eGFR even in patients without diabetes mellitus or hypertension, with an AAPC of $-0.80 \%(95 \% \mathrm{Cl}-0.99$ to $-0.62 ; P=0.002)$, and $0.87 \%$ (95\% Cl -1.07 to $-0.67 ; P=0.001$ ), respectively. If either diabetes or hypertension was present, the decline in eGFR showed a trend toward more accelerated patterns; an AAPC of $-1.59 \%(95 \% \mathrm{Cl},-2.29$ to -0.89 ; $P=0.011)$ and $-1.00 \%(95 \% \mathrm{Cl},-1.29$ to $-0.70 ; P=0.002)$ in patients with diabetes and hypertension, respectively.

\section{Predictors of ongoing renal dysfunction}


During the 6-year observation period after the commencement of AVT, a total of 681 (22.4\%) patients developed ongoing renal dysfunction, which was defined as a negative slope of the mean change in eGFR during AVT. Table 3 shows the comparison of the characteristics of patients with and without ongoing renal dysfunction. The group with ongoing renal dysfunction had older patients, a higher proportion of those with diabetes mellitus, hypertension, and liver cirrhosis, who received treatment with TDF (all p 0.05 ), and had lower serum albumin and eGFR at 1 year of AVT, compared to those without.

\section{Table 3. Comparison of patients with and without ongoing renal dysfunction}




\section{Variables}

Age (years)

Male gender

Body mass index $(\mathrm{kg} / \mathrm{m} 2)$

Diabetes mellitus

Hypertension

Liver cirrhosis

HBeAg positivity

HBV- DNA $\left(\log _{10} \mathrm{lU} / \mathrm{ml}\right)$

AST (IU/L)

ALT (IU/L)

Serum albumin $(\mathrm{g} / \mathrm{dL})$

Total bilirubin $(\mathrm{g} / \mathrm{dl})$

Gamma-glutamyl transpeptidase

(IU/L)

Platelet count $\left(\times 10^{9} / \mathrm{L}\right)$

Prothrombin time (INR)

Serum $\mathrm{Na}(\mathrm{mmol} / \mathrm{L})$

Creatinine $(\mathrm{mg} / \mathrm{dL})$

eGFR by CKD-EPI $\left(\mathrm{ml} / \mathrm{min} / 1.73 \mathrm{~m}^{2}\right)$

TDF (vs. ETV)
Preserved renal function $(n=2,352)$

$47.2 \pm 10.9$

1,505 (64.0)

$23.7 \pm 3.1$

$186(7.9)$

$186(7.9)$

611 (26.0)

$1,220(51.9)$

$5.2 \pm 6.7$

$30 \pm 24$

$32 \pm 40$

$4.4 \pm 0.4$

$0.9 \pm 0.4$

$79 \pm 95$

$166 \pm 75$

$1.0 \pm 0.2$

$140 \pm 3$

$0.9 \pm 0.2$

$100.0 \pm 18.9$

$2,116(9.1)$
Ongoing renal dysfunction

$(n=681)$

$48.7 \pm 11.2$

456 (37.0)

$23.6 \pm 2.7$

81(11.9)

88 (12.9)

219 (32.2)

317 (46.5)

$5.1 \pm 4.2$

$30 \pm 18$

0.866

$30 \pm 23$

0.566

$4.3 \pm 0.4$

$<0.001$

$0.8 \pm 0.7$

0.060

$77 \pm 90$

0.320

$165 \pm 70$

0.741

$0.9 \pm 0.2$

0.017

$141 \pm 3$

0.411

$0.8 \pm 0.2$

$<0.001$

$92.6 \pm 17.5$

$<0.001$

$154(22.6)$

$<0.001$

Variables are expressed as mean \pm standard deviation or no. (\%).

Abbreviations: HBeAg; hepatitis B e antigen; HBV, hepatitis B virus; AST, aspartate aminotransferase; ALT, alanine aminotransferase; INR, international normalized ratio; CKD-EPI, Chronic Kidney Disease Epidemiology Collaboration equation; TDF, tenofovir disoproxil fumarate; ETV, entecavir

On univariate analysis, significant factors associated with ongoing renal dysfunction were age $>60$ years (OR 1.557, 95\% Cl 1.169-2.075; $p=0.002$ ), hypertension (OR 2.667, 95\% Cl 1.931-3.684; $p<0.001$ ), diabetes mellitus (OR 1.861, 95\% Cl 1.292-2.681; $\mathrm{p}<0.001)$, eGFR $<60 \mathrm{~mL} / \mathrm{min} / 1.73 \mathrm{~m}^{2}$ at 1 year of AVT (OR 1.963, 
$95 \% \mathrm{Cl} 1.285-2.996 ; \mathrm{p}=0.002$ ), serum albumin $<3.5 \mathrm{mg} / \mathrm{dL}$ at 1 year of AVT (OR 2.128, 95\% Cl 1.453$3.117 ; p<0.001)$, and treatment with TDF (OR 1.572, 95\% Cl 1.242-1.989; $p<0.001)$. Subsequently, these univariate predictors were entered into the multivariate logistic regression model, showing that treatment with TDF (adjusted OR [aOR], 1.656; 95\% Cl 1.303-2.107; $P<0.001$; Table 4) proved to be an independent risk factor, along with hypertension (aOR 2.356, 95\% Cl 1.664-3.334; $P<0.001$ ), eGFR $<60 \mathrm{~mL} / \mathrm{min} / 1.73 \mathrm{~m}^{2}$ at 1 year of AVT (aOR 1.823,95\% Cl 1.179-2.821; $P=0.001$ ), and serum albumin at 1 year of AVT (aOR 2.023, 95\% Cl 1.370-2.988; $P<0.001)$.

\section{Table 4. Risk factors of ongoing renal dysfunction}

\begin{tabular}{|c|c|c|c|c|}
\hline \multirow[t]{2}{*}{ Variables } & \multicolumn{2}{|c|}{ Univariate analysis } & \multicolumn{2}{|c|}{ Multivariate analysis } \\
\hline & OR $(95 \% \mathrm{Cl})$ & $\begin{array}{l}P \\
\text { value }\end{array}$ & $\begin{array}{l}\text { Adjusted OR (95\% } \\
\text { Cl) }\end{array}$ & $\begin{array}{l}P \\
\text { value }\end{array}$ \\
\hline Male & $\begin{array}{l}1.140(0.896- \\
1.450)\end{array}$ & 0.285 & & \\
\hline Age $>60$ years & $\begin{array}{l}1.557(1.169- \\
2.075)\end{array}$ & 0.002 & $\begin{array}{l}1.249(0.925- \\
1.688)\end{array}$ & 0.147 \\
\hline Hypertension & $\begin{array}{l}2.667(1.931- \\
3.684)\end{array}$ & $<0.001$ & $\begin{array}{l}2.356(1.664- \\
3.334)\end{array}$ & $<0.001$ \\
\hline Diabetes mellitus & $\begin{array}{l}1.861(1.292- \\
2.681)\end{array}$ & 0.001 & $\begin{array}{l}1.387(0.934- \\
2.059)\end{array}$ & 0.105 \\
\hline Liver cirrhosis & $\begin{array}{l}1.286(0.999- \\
1.654)\end{array}$ & 0.051 & & \\
\hline $\begin{array}{l}\text { eGFR }<60 \mathrm{~mL} / \mathrm{min} / 1.73 \mathrm{~m} 2 \text { at } 1 \text { year of } \\
\text { AVT }\end{array}$ & $\begin{array}{l}1.963(1.285- \\
2.996)\end{array}$ & 0.002 & $\begin{array}{l}1.823(1.179- \\
2.821)\end{array}$ & 0.007 \\
\hline Albumin $<3.5 \mathrm{mg} / \mathrm{dL}$ at 1 year of AVT & $\begin{array}{l}2.128(1.453- \\
3.117)\end{array}$ & $<0.001$ & $\begin{array}{l}2.023(1.370- \\
2.988)\end{array}$ & $<0.001$ \\
\hline TDF (vs. ETV) & $\begin{array}{l}1.572(1.242- \\
1.989)\end{array}$ & $<0.001$ & $\begin{array}{l}1.656(1.303- \\
2.107)\end{array}$ & $<0.001$ \\
\hline
\end{tabular}

Abbreviations: , OR, odds ratio; Cl, confidence interval; eGFR, estimated glomerular filtration rate; AVT, antiviral therapy; TDF, tenofovir disoproxil fumarate; ETV, entecavir

\section{Discussion}

The most recent guidelines from the European Association for the Study of the Liver (EASL) recommend ETV or tenofovir alafenamide (TAF) over ETV in CHB patients with renal insufficiency or its risk factors [4]. Although there have been several studies reporting no difference in renal function between patients treated with TDF and those treated with ETV during a relatively short observation period [14, 15, 24, 25], TDF has the inherent potential to be nephrotoxic. Because TDF accumulates in the proximal tubule during its excretion through the kidney, it causes nephrotoxicity through direct proximal tubular cell and 
mitochondrial damage $[26,27]$. In this study, we confirmed that eGFR significantly decreased in the TDF group (AAPC -0.88\%, $P<0.001$ ) during the 6-year observation period after the commencement of AVT, in contrast to the ETV group wherein the eGFR was maintained (AAPC $-0.09 \%, P=0.322$ ).

Our findings have several strengths. First, we provide robust evidence to support the above EASL guidelines based on real-world data, emphasizing that special attention needs to be paid to serial changes in renal function, especially in the group receiving TDF, given that AVT treatment is usually lifelong $[16,17,28,29]$. Second, compared to previous studies, our study has the advantage of a longer follow-up duration (up to 6 years) and a larger sample size $(n=3,033)$ from three independent academic teaching hospitals in a real-world setting. Furthermore, from a statistical perspective, we focused on annual changes in the eGFR. In fact, in most previous studies, the occurrence of CKD of or eGFR reduction by $\geq 20 \%$ was adopted as the major study endpoint $[16,24,30]$. However, given that the annual decline in eGFR among the TDF group, although progressive, was not so rapid, the actual number of events fulfilling the occurrence of overt CKD, i.e. eGFR $60 \mathrm{~mL} / \mathrm{min} / 1.73 \mathrm{~m}^{2}$ or eGFR reduction by $\geq 20 \%$ was very small $(3.7-6.8 \%$ in other studies; $3.7 \%$ in our study) $[16,24,30]$. In such circumstances, there may be a statistically significant concern leading to the false negativity of the type II error. For this reason, we focused on the AAPC in eGFR during the long-term AVT, using Joinpoint regression and adopted a negative slope of the mean change in eGFR during the AVT $(n=681,22.4 \%)$ as the major clinical endpoint in the logistic regression. To the best of our knowledge, this study is the first to assess AAPC in eGFR during long-term AVT in patients with $\mathrm{CHB}$.

Notably, in contrast to the ETV group, even patients without diabetes mellitus or hypertension in the TDF group showed significantly decreased eGFR, with AAPCs of $-0.80 \%$ and $-0.87 \%$, respectively. As expected, when diabetes mellitus or hypertension was present in the TDF group, the decline in eGFR showed a trend toward more accelerated patterns: an AAPC of $-1.59 \%$ and $-1.00 \%$, respectively. Physicians should monitor patients' renal function more closely, considering that therapy with TDF is almost life-long. Although patients in the ETV group with diabetes mellitus or hypertension may also experience a significant decline in eGFR, this may be due to the natural history of the accompanying comorbidities rather than an ETV-related adverse event. Nevertheless, given that patients with $\mathrm{CHB}$ are aging, and their comorbidities (e.g., diabetes, hypertension, and chronic kidney disease) are also increasing [9, 31], the early recognition of individual risk factors and correspondingly careful monitoring are also required

The TDF-induced eGFR decrease observed in this study occurred consistently every year after the first year of AVT. There are conflicting opinions regarding whether the renal impairment induced by TDF is prominent early since the beginning of AVT [32] or progressive after several years of AVT [13]. Therefore, further research is needed to investigate the timing of the development of TDF-induced renal toxicity, its degree, and annual progress rate. Specifically, a long-term study of up to 10 years or longer is needed to determine whether the eGFR will continue to drop or there will be a quiescent period. This would provide an important clinical insight into whether TDF should be sustained or replaced with safer oral NUCs that is, ETV or TAF at a certain time point. 
An eGFR $<60 \mathrm{~mL} / \mathrm{min} / 1.73 \mathrm{~m}^{2}$ and a low albumin level at 1 year of AVT as well as hypertension were independent predictors of ongoing renal dysfunction in our study. Diabetes mellitus was a significant univariate predictor, but did not prove to be independently associated with ongoing renal dysfunction in the multivariate analysis; this is different from the general hypothesis that diabetes mellitus is a wellknown risk factor for progression to CKD. This is most likely due to the multi-collinearity of diabetes with hypertension. Indeed, patients with diabetes mellitus were more likely to have hypertension than those without $(31.6 \%$ vs. $6.9 \%$; OR, $6.20 ; 95 \% \mathrm{Cl}, 4.57-8.42 ; P<0.001)$. Consistent with the findings of previous studies, baseline eGFR $<60 \mathrm{~mL} / \mathrm{min} / 1.73 \mathrm{~m}^{2}$ was a poor prognostic factor in our study [24, 32], indicating that more caution is required in such a population during follow-up. In addition, albumin synthesis decreases as a result of liver dysfunction in patients with chronic liver disease, and may lead to decreased effective intravascular blood volume, compensatory activation of the renin-angiotensin system and sympathetic nervous system, sodium and water retention, and finally, reduction in renal perfusion and eGFR $[33,34]$.

This study has several limitations. First, the retrospective design may have led to an inherent selection bias, which we tried to overcome by recruiting a homogeneous study population with a statistically reliable large sample size and event number, providing a longer follow-up duration, gathering data from multiple centers (three independent teaching hospital)s, and applying optimized statistical approaches. However, additional studies are required to validate this hypothesis. Finally, the analyses of new biomarkers for $\mathrm{CHB}$ (e.g., serum quantitative hepatitis B surface antigen, serum hepatitis B core-related antigen, serum HBV-RNA, or specific HBV mutants), and for renal insufficiency (i.e., cystatin C, $\beta 2$ microglobulin, or neutrophil gelatinase-associated lipocalin) may provide more precise predictions in the future $[13,35]$.

In conclusion, compared to the ETV group, the TDF group experienced slow, but progressive renal dysfunction. Although the annual eGFR change was small in the TDF group, careful monitoring of renal function is necessary to allow timely intervention, especially in patients requiring life-long AVT.

\section{Abbreviations}

CHB, chronic hepatitis B; AVT, antiviral therapy; ETV, entecavir; TDF, tenofovir disoproxil fumarate; eGFR, estimated glomerular filtration rate; HBV, hepatitis B virus; HCC, hepatocellular carcinoma; NUC, nucleos[t]ide analogue; CKD-EPI, Chronic Kidney Disease Epidemiology Collaboration; AST, aspartate aminotransferase; ALT, aspartate aminotransferase; UNL, upper normal limit; OR, odds ratio; $\mathrm{Cl}$, confidence interval; EASL; the European Association for the Study of the Liver; TAF, tenofovir alafenamide.

\section{Declarations}

Data availability: Available on request to corresponding author. 
Animal Research (Ethics): Not applicable.

Consent to participant (Ethics): Informed consent was waived because of the retrospective nature of the study.

\section{Consent to Publish (Ethics): Yes}

Reproducibility: Yes

Clinical Trials Registration: IRB 2020-06-035

\section{Author contributions}

Conception: Beom Kyung Kim and Soo Young Park; study design: Soo Young Park, Young Eun Chon and Beom Kyung Kim; participation in patient management and data collection: Seung Up Kim, Young Eun Chon, Soo Young Park, Jae Seung Lee, Hye Won Lee, Mi Na Kim, Jun Yong Park, Do Young Kim, Sang Hoon Ahn, and Beom Kyung Kim; contribution to the data acquisition, responsibility for writing the paper, and statistical analysis: Han Pyo Hong, Young Eun Chon, Beom Kyung Kim, and Soo Young Park.

All authors have reviewed the paper and approved the final version.

Conflict of interest: None.

\section{Funding: None}

\section{References}

1. Global prevalence. treatment, and prevention of hepatitis B virus infection in 2016: a modelling study. Lancet Gastroenterol Hepatol. 2018;3(6):383-403. https://doi.org/10.1016/s2468-1253(18)30056-6.

2. Chen YC, Chu CM, Yeh CT, Liaw YF. Natural course following the onset of cirrhosis in patients with chronic hepatitis B: a long-term follow-up study. Hepatol Int. 2007;1(1):267-73. https://doi.org/10.1007/s12072-007-5001-0.

3. Iloeje UH, Yang HI, Su J, Jen CL, You SL, Chen CJ. Predicting cirrhosis risk based on the level of circulating hepatitis B viral load. Gastroenterology. 2006;130(3):678-86. https://doi.org/10.1053/j.gastro.2005.11.016.

4. EASL. 2017 Clinical Practice Guidelines on the management of hepatitis B virus infection. J Hepatol. 2017;67(2):370-398. https://doi.org/10.1016/j.jhep.2017.03.021.

5. KASL clinical practice guidelines for management of chronic hepatitis B. Clin Mol Hepatol. 2019;25(2):93-159. https://doi.org/10.3350/cmh.2019.1002.

6. Terrault NA, Lok ASF, McMahon BJ, Chang KM, Hwang JP, Jonas MM, et al. Update on prevention, diagnosis, and treatment of chronic hepatitis B: AASLD 2018 hepatitis B guidance. Hepatology. 2018;67(4):1560-99. https://doi.org/10.1002/hep.29800. 
7. Yim HJ, Kim JH, Park JY, Yoon EL, Park H, Kwon JH, et al. Comparison of clinical practice guidelines for the management of chronic hepatitis B: When to start, when to change, and when to stop. Clin Mol Hepatol. 2020;26(4):411-29. https://doi.org/10.3350/cmh.2020.0049.

8. Liang LY, Wong GL. Unmet need in chronic hepatitis B management. Clin Mol Hepatol. 2019;25(2):172-80. https://doi.org/10.3350/cmh.2018.0106.

9. Oh H, Jun DW. Increasing comorbidities in a South Korea insured population-based cohort of patients with chronic hepatitis B. 2020;52(2):371-381. https://doi.org/10.1111/apt.15867.

10. Bucsics T, Krones E. Renal dysfunction in cirrhosis: acute kidney injury and the hepatorenal syndrome. Gastroenterol Rep (Oxf). 2017;5(2):127-37. https://doi.org/10.1093/gastro/gox009.

11. Hwang HS, Park CW, Song MJ. Tenofovir-associated Fanconi syndrome and nephrotic syndrome in a patient with chronic hepatitis B monoinfection. Hepatology. 2015;62(4):1318-20. https://doi.org/10.1002/hep.27730.

12. Viganò $M$, Brocchieri A, Spinetti A, Zaltron S, Mangia G, Facchetti F, et al. Tenofovir-induced Fanconi syndrome in chronic hepatitis $B$ monoinfected patients that reverted after tenofovir withdrawal. J Clin Virol. 2014;61(4):600-3. https://doi.org/10.1016/j.jcv.2014.09.016.

13. Koksal AR, Alkim H, Boga S, lyisoy MS, Sen I, Tekin Neijmann S, et al. Value of Cystatin C-Based eGFR Measurements to Predict Long-Term Tenofovir Nephrotoxicity in Patients With Hepatitis B. Am J Ther. 2019;26(1):e25-31. https://doi.org/10.1097/mjt.0000000000000518.

14. Ha NB, Ku K, Ha NB, Chaung KT, Trinh HN, Nguyen MH. Renal Function in Chronic Hepatitis B Patients Treated With Tenofovir Disoproxil Fumarate or Entecavir Monotherapy: A Matched CaseCohort Study. J Clin Gastroenterol. 2015;49(10):873-7. https://doi.org/10.1097/mcg.0000000000000325.

15. Mallet V, Schwarzinger $M$, Vallet-Pichard A, Fontaine $H$, Corouge $M$, Sogni $P$, et al. Effect of nucleoside and nucleotide analogues on renal function in patients with chronic hepatitis $B$ virus monoinfection. Clin Gastroenterol Hepatol. 2015;13(6):1181-8.e1181. https://doi.org/10.1016/j.cgh.2014.11.021.

16. Tsai MC, Chen $\mathrm{CH}$, Tseng PL, Hung $\mathrm{CH}$, Chiu KW, Chang KC, et al. Does Nucleos(t)ide Analogues Treatment Affect Renal Function in Chronic Hepatitis B Patients Who Have Already Decreased eGFR? A Longitudinal Study. PLoS One. 2016;11(3):e0149761. https://doi.org/10.1371/journal.pone.0149761.

17. Koklu S, Gulsen MT, Tuna Y, Koklu H, Yuksel O, Demir M, et al. Differences in nephrotoxicity risk and renal effects among anti-viral therapies against hepatitis B. Aliment Pharmacol Ther. 2015;41(3):310-9. https://doi.org/10.1111/apt.13036.

18. Wong GL, Chan HL. Chronic kidney disease progression in patients with chronic hepatitis B on tenofovir, entecavir, or no treatment. 2018;48(9):984-992. https://doi.org/10.1111/apt.14945.

19. Esfeh JM, Hajifathalian K, Ansari-Gilani K. Sensitivity of ultrasound in detecting hepatocellular carcinoma in obese patients compared to explant pathology as the gold standard. Clin Mol Hepatol. 2020;26(1):54-9. https://doi.org/10.3350/cmh.2019.0039. 
20. Yang JD. Detect or not to detect very early stage hepatocellular carcinoma? The western perspective. Clin Mol Hepatol. 2019;25(4):335-43. https://doi.org/10.3350/cmh.2019.0010.

21. Shin H, Jung YW, Kim BK, Park JY, Kim DY, Ahn SH, et al. Risk assessment of hepatocellular carcinoma development for indeterminate hepatic nodules in patients with chronic hepatitis $\mathrm{B}$. Clin Mol Hepatol. 2019;25(4):390-9. https://doi.org/10.3350/cmh.2018.0103.

22. Maruyama $\mathrm{H}$, Kato $\mathrm{N}$. Advances in ultrasound diagnosis in chronic liver diseases. Clin Mol Hepatol. 2019;25(2):160-7. https://doi.org/10.3350/cmh.2018.1013.

23. Levey AS, Stevens LA, Schmid CH, Zhang YL, Castro AF 3rd, Feldman HI, et al. A new equation to estimate glomerular filtration rate. Ann Intern Med. 2009;150(9):604-12. https://doi.org/10.7326/0003-4819-150-9-200905050-00006.

24. Park J, Jung KS, Lee HW, Kim BK, Kim SU, Kim DY, et al. Effects of Entecavir and Tenofovir on Renal Function in Patients with Hepatitis B Virus-Related Compensated and Decompensated Cirrhosis. Gut Liver. 2017;11(6):828-34. https://doi.org/10.5009/gnl16484.

25. López Centeno B, Collado Borrell R, Pérez Encinas M, Gutiérrez García ML, Sanmartin Fenollera P. Comparison of the effectiveness and renal safety of tenofovir versus entecavir in patients with chronic hepatitis B. Farm Hosp. 2016;40(4):279-86. https://doi.org/10.7399/fh.2016.40.4.10492.

26. Gitman MD, Hirschwerk D, Baskin CH, Singhal PC. Tenofovir-induced kidney injury. Expert Opin Drug Saf. 2007;6(2):155-64. https://doi.org/10.1517/14740338.6.2.155.

27. Jafari A, Khalili H, Dashti-Khavidaki S. Tenofovir-induced nephrotoxicity: incidence, mechanism, risk factors, prognosis and proposed agents for prevention. Eur J Clin Pharmacol. 2014;70(9):1029-40. https://doi.org/10.1007/s00228-014-1712-z.

28. Chen YC, Su YC, Li CY, Hung SK. 13-year nationwide cohort study of chronic kidney disease risk among treatment-naïve patients with chronic hepatitis B in Taiwan. BMC Nephrol. 2015;16:110. https://doi.org/10.1186/s12882-015-0106-5.

29. Maggi P, Montinaro V, Leone A, Fasano M, Volpe A, Bellacosa C, et al. Bone and kidney toxicity induced by nucleotide analogues in patients affected by HBV-related chronic hepatitis: a longitudinal study. J Antimicrob Chemother. 2015;70(4):1150-4. https://doi.org/10.1093/jac/dku502.

30. Jung CY, Kim HW, Ahn SH, Kim SU, Kim BS. Tenofovir is Associated With Higher Risk of Kidney Function Decline Than Entecavir in Patients With Chronic Hepatitis B. Clin Gastroenterol Hepatol. 2021. https://doi.org/10.1016/j.cgh.2021.05.032.

31. Park SH, Plank LD, Suk KT, Park YE, Lee J, Choi JH, et al. Trends in the prevalence of chronic liver disease in the Korean adult population, 1998-2017. Clin Mol Hepatol. 2020;26(2):209-15. https://doi.org/10.3350/cmh.2019.0065.

32. Lim TS, Lee JS. An observational study on long-term renal outcome in patients with chronic hepatitis B treated with tenofovir disoproxil fumarate. 2020;27(3):316-322. https://doi.org/10.1111/jvh.13222.

33. Carvalho JR, Verdelho Machado M. New Insights About Albumin and Liver Disease. Ann Hepatol. 2018;17(4):547-60. https://doi.org/10.5604/01.3001.0012.0916. 
34. EASL clinical practice guidelines on the management of. ascites, spontaneous bacterial peritonitis, and hepatorenal syndrome in cirrhosis. J Hepatol. 2010;53(3):397-417. https://doi.org/10.1016/j.jhep.2010.05.004.

35. Inoue T, Tanaka Y. Novel biomarkers for the management of chronic hepatitis B. Clin Mol Hepatol. 2020;26(3):261-79. https://doi.org/10.3350/cmh.2020.0032.

Figures

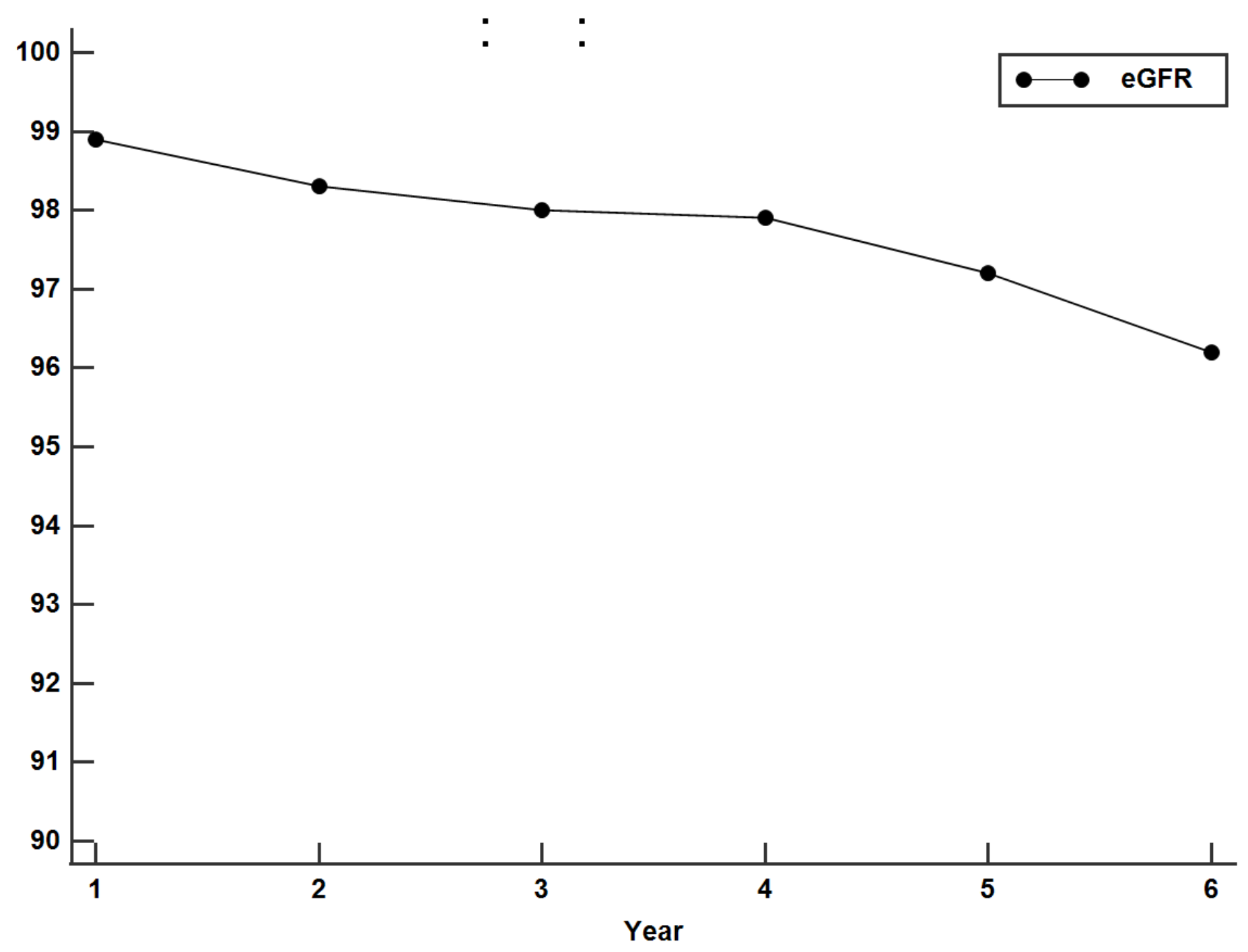

Figure 1

Changes in estimated glomerular filtration rate (eGFR) during long-term antiviral therapy (AVT) among the entire population 


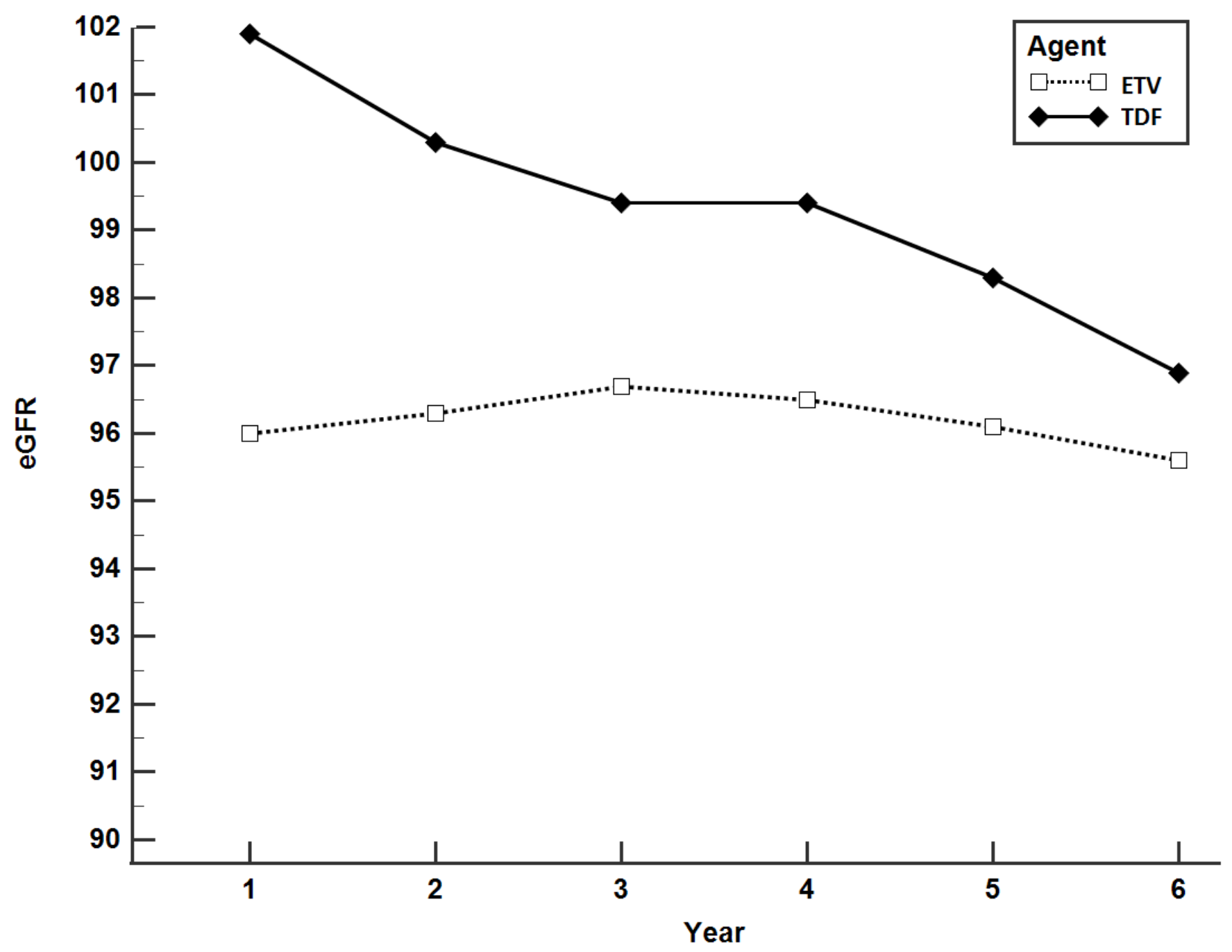

Figure 2

Changes in estimated glomerular filtration rate (eGFR) according to treatment with either entecavir (ETV) or tenofovir disoproxil fumarate (TDF)

\section{Supplementary Files}

This is a list of supplementary files associated with this preprint. Click to download.

- Supplementarydata.docx 